\title{
Computer Research Project Management
}

\author{
Towards ontology based approach for Research Projects
}

\author{
Lassad Mejri ${ }^{1}$ \\ Jouf University - Saudia Arabia \\ College of Computer Science \& Information \\ Carthage University \\ Faculty of Science in Bizerta, Tunisia
}

\author{
Henda Hajjami Ben Ghezala ${ }^{2}$, Raja Hanafi ${ }^{3}$ \\ National School of Computer \\ University of Manouba
}

Tunisia

\begin{abstract}
Most research project managers, laboratories directors, young researchers at the beginning stage of thesis or professional research projects leaders are well effective at dealing with planned, scheduled events - they know how to function in conducting their research projects according to traditional knowledge areas of classical processes lied to time, cost, human resources, risk, stakeholders, and quality management. Unfortunately, they may have little specific training in selecting the best thematic of research. Indeed, they have no experience in identifying adequate research problems. Despite their motivation for the selected project and research thematic, they don't well master research problematic and how to deal with: Literature for the selected thematic of research: (Sources, Documents, reports and technical folders): List of problems encountered during the research theme conducting and how to make profit of the obtained solutions approaches for these kinds of research problems. - How to decide if this research theme and the list of connected problems are already resolved or not by any other research team. This paper aims to develop this idea and finally to propose ontology named "Onto-Research-Project" that formalizes all the domain knowledge of computer research projects. Our final goal is to propose an approach for historical research projects reusing. The output of this approach is a computer research project memory. In this way, we have to make use and to restructure the knowledge obtained from the research computer projects stored in the database "HAL-ArchivesNouvelles".
\end{abstract}

Keywords-Research projects; computer research project ontology; knowledge management; project memory

\section{INTRODUCTION}

Research projects in general are much diversified. They occupied naturally many years of deeper studies and experimentations to make a valid proposal. They make use of many knowledge sources and experimented human resources. Research projects in the field of computer sciences and engineering require organized and methodological steps to achieve predefined goals. Indeed, these kinds of projects involve a conception phase which combines different reasoning modes, techniques and tools to design a final system which makes this kind of research projects more complex. Research projects in the domain of computer sciences and computer engineering often result in designing algorithms, models and approaches able to solve initial research problems. These multiple problems generally involve knowledge about different concepts, terms, languages, and vocabularies. In general [1], anthologies play now a major role in the representation, organization and in the modeling of different and heterogeneous knowledge. Their main objective is to formalize the knowledge of a domain and thus add a semantic layer to computer systems and applications. In addition, the development of a new ontology makes it possible to explicitly represent the knowledge of a domain by means of a formal language, in order to be able to be manipulated automatically and shared easily.

Indeed, ontology consists of a set of concepts organized using hierarchical and specialized relationships representing a means of expression, sharing and reuse of knowledge, usable by all actors involved in the project. In computer engineering projects, construction methods and software techniques occupy an important place. Moreover, this domain makes use of many concepts, terms, languages, processes, models and methods of resolution. This fact involves the importance of using ontology to structure and to model all the concepts, the diverse knowledge that we would like to model.

In research projects, most research project managers, laboratories directors, young researchers at the beginning stage of thesis or professional research projects leaders are well effective at dealing with planned, scheduled events - they know how to function in conducting their research projects according to traditional knowledge areas of classical processes lied to time, cost, human resources (research teams), risk, stakeholders, and quality management. Unfortunately, they may have little specific training in how to select the best thematic of research. Indeed, they have no experience in identifying adequate research problems. Despite their motivation for the selected project and the selected research thematic they don't master well research problematic and how to deal with.

This paper aimed at elaborating an ontology based approach to give a helpful tool dedicated to researchers in the domain of computer sciences and engineering. This approach makes use of ontology of the domain to generate an aid at many levels:

- To help young researchers to select their adequate research theme.

- To help them to identify the adequate research problems.

- To give an aid in literature phase of research. 
- To look for different research suggestions and/or solutions proposed by researchers in historical research projects similar to the new project.

Our paper is organized as follows. After the introduction, Section 2 consists of the state of the art which is composed of two sub-sections: In the first Sub-section, we will describe both the main related works of project memory approaches and a discussion study.

In the second sub-section the ontology elaborating methodologies are reviewed and finally a comparative study between these methodologies is discussed. Section 3 presents the modeling phase which consists in models description and giving finally our domain ontology for research projects. Section 4 consists of a proposal of an approach based on this ontology. Finally Section 5 is assigned to the conclusion and opens future works.

\section{STATE OF THE ART}

The state-of-the-art consists essentially of two parts: The first one focuses on project memory concepts and their utility for the knowledge capitalization purposes. The second one reveals a state of the art on the methods of ontological elaboration and a comparative study of the available methodologies. In the following, we introduce the major works in the literature associated with the project memory concepts.

\section{A. Computer Project Memory}

The concept of "computer project memory" is not famous in literature compared with the general known concept of "Project Memory" or "Corporate memory". We try here to introduce a research study to underline the concept of "Computer Project Memory". Indeed, for the past 20 years, computers have literally invaded businesses. They have developed many computer services [2] in order to manage, conduct, support and follow computer projects.

In the context of managing a computer project, there are constraints inherent to the information system of a company.

At the first, we could underline the increased user requirements, in particular as regards ergonomics.

Secondly, we could refer to the additional difficulties brought about by computer technologies.

Finally, a computer project is characterized by an intrinsic difficulty since this type of project is related to a software complexity [3].

Hence, it is essential to refer to a method of project management. This method helps designers better conduct this type of project stage by stage and use well-defined modeling tools [4].

In addition, purely computer projects are quite varied in view of the diversity of their sub-domains; Such as databases, smart systems, design resources, and software engineering. Hence, there is a major interest to restructure the knowledge of the computer domain by the construction of a "computer project memory".
1) Concept of project memory: Let us now, looking for the term of project memory in general and not essentially lied to computer projects.

According to [5], a "project memory" is a very limited part of a capitalization exercise of a whole range of diverse experiences in the business. This memory aims at the traceability and the re-use of similar projects. It consists essentially of two components:

- The problem-solving context.

- The method of resolution.

In [6] the "project memory" was considered as a technique that approximates the meeting often done at the end of the project because it seeks to determine the same knowledge and lessons learned during the project. Furthermore, the "project memory" is established throughout the implementation of the project and not at the end.

According to [7] "project memory" can be defined as a memory of project knowledge. It is an appropriation of the knowledge acquired over time of the activity of the company. The development of project memory is a procedure whose implementation requires some basic assumptions:

- The Project Memory is essentially formed and represented by database structure.

- The project memory is a tool for sharing accessibility based on the demand of this database.

- The project memory refers to the principle of community: "an individual effort at the service of the community".

According to [8] a project memory is the procedure that keeps track of actions performed in the arrangement of a project. It makes it possible to find the person responsible for a decision taken beforehand. This technique also allows the reuse of projects that are already realized in order to reduce the cost and the time.

According to [9] "a project memory" must contain in the first part the information describing the problem-solving and the decision-making. The second part represents the characteristics and the context of the said project.

Through these different definitions, we can consider "project memory" as the storage and the retention processes of the history during the realization of a given project. It therefore contains all the information, know-how, knowledge and skills that will be used by experts to achieve project goals.

2) Synthesis of computer project memory concepts: During our research study, we noticed that the researchers in memory projects domain based their research on two main directions:

Direction 1: Typologies of memories (classifications).

Direction 2: Project memory models.

a) Typologies of memories (classifications): We present in the table below (Table I) a summary study of the 
classifications of corporate memories given in literature. The Table I presents the kind of memory and the knowledge resources manipulated by each kind of organization memory. Corporate memory seems to be a solution for preserving and sharing knowledge that has come from different sources and fields. In addition, we notice that the «project memory» is almost present in all the classifications that we mentioned in Table I.

This shows us the importance and usefulness of this memory in the knowledge management.

TABLE I. SUMMARY OF THE CORPORATE MEMORY ClaSSIFICATION

\begin{tabular}{|c|c|c|}
\hline Classification & Type of Memory & manipulated data \\
\hline \multirow{5}{*}{$\begin{array}{l}\text { Marinella 's \& all } \\
\text { classification } \\
\text { [10] }\end{array}$} & Documentary memory & Documents \\
\hline & Memory based on case & $\begin{array}{l}\text { Problems, solutions, } \\
\text { experiences. }\end{array}$ \\
\hline & $\begin{array}{l}\text { Memory based on } \\
\text { knowledge }\end{array}$ & Knowledge, text \\
\hline & hybrid Memory & $\begin{array}{l}\text { Knowledge, text, data, } \\
\text { documents, ontology, } \\
\text { annotations }\end{array}$ \\
\hline & groupware Memory & $\begin{array}{l}\text { Interventions, } \\
\text { messages, mails }\end{array}$ \\
\hline \multirow{3}{*}{$\begin{array}{l}\text { Classification } \\
\text { Of } \\
\text { André [11] }\end{array}$} & $\begin{array}{l}\text { Semantics } \\
\text { memory }\end{array}$ & $\begin{array}{l}\text { knowledge, symbols, logical } \\
\text { references }\end{array}$ \\
\hline & Procedural memory & $\begin{array}{l}\text { methods, strategies, } \\
\text { structures, procedures }\end{array}$ \\
\hline & Episodic memory & facts, episodes, events \\
\hline \multirow{3}{*}{$\begin{array}{l}\text { Classification } \\
\text { Of } \\
\text { Pominant [12] }\end{array}$} & Project memory & Projects, experiences, tracks \\
\hline & Organizational memory & Competencies, know-how \\
\hline & Technical memory & experiences, papers \\
\hline \multirow{4}{*}{$\begin{array}{l}\text { Classification of } \\
\text { Dieng et al [13] }\end{array}$} & Memory of profession & Experiences, professions, \\
\hline & Company memory & $\begin{array}{l}\text { Document, know-how, } \\
\text { know }\end{array}$ \\
\hline & Individual memory & $\begin{array}{l}\text { Contact information, } \\
\text { judgment, historic... }\end{array}$ \\
\hline & Project memory & $\begin{array}{l}\text { Experiences, results, } \\
\text { solutions }\end{array}$ \\
\hline \multirow{2}{*}{$\begin{array}{l}\text { Classification of } \\
\text { Ben Sta [9] }\end{array}$} & Long-term memory & long term information \\
\hline & Short term memory & Short term information \\
\hline \multirow{4}{*}{$\begin{array}{l}\text { Classification of } \\
\text { Bascans } \\
\text { [14] }\end{array}$} & Business memory & documents, tools, reference, \\
\hline & Corporate memory & $\begin{array}{l}\text { business, products, } \\
\text { partnership }\end{array}$ \\
\hline & Individual memory & statue, skills, know how \\
\hline & Project memory & $\begin{array}{l}\text { history, results, activities, } \\
\text { experiences }\end{array}$ \\
\hline
\end{tabular}

Since a project is a unique process that consists of a set of coordinated and controlled activities, knowledge, information and experiences. The concept of "project memory" seems to be the best way to contribute efficiently to solve our research problem which consists to manage experiences and knowledge about past research projects in the way to resolve the new project.

b) Project memory models: Several project memory models are presented in the literature. Inspired from, we present our classification in (Table II). This classification is based on a set of criteria chosen by us:

- Decision making: this criterion permits to verify whether the proposed model takes into account the decision-making process in research project.

- Project context: is the set of elements characterizing the organization \& environment factors of project. For each model proposed we will see if it guarantees the capitalization of the project context.

- Rationale design: is the problem solving process, this criterion checks if the model allows or not the capitalization of the logic design.

- Project characteristics: describes the set of elements: actors, materials, tools, processes and documents related to the project.

- Reuse: it expresses the possibility of reusing the project memory in future.

- Generic or specific: Checks if the model can be used for any type of project or it is simply specific to only one kind of project.

According to Bekhti [16], project memory is composed of two parts: the first one presents the design logic and the second presents the project context.

Harani [17] has proposed another generic model that is composed of three models (product model, process model and resource model). His proposal is structured on three levels: meta-model, specification and realization.

Labrousse [15] has proposed a model that is based on the integration of these concepts: product, process and resource. This model is defined by the roles played by these different concepts.

TABLE II. Summary of THE Project Memory Models

\begin{tabular}{|l|l|l|l|l|l|l|}
\hline Model & $\begin{array}{l}\text { decision } \\
\text { making }\end{array}$ & $\begin{array}{l}\text { project } \\
\text { context }\end{array}$ & $\begin{array}{l}\text { design } \\
\text { logic }\end{array}$ & $\begin{array}{l}\text { project } \\
\text { feature }\end{array}$ & reuse & $\begin{array}{l}\text { generic } \\
\text { specific }\end{array}$ \\
\hline $\begin{array}{l}\text { Labrousse } \\
{[\mathbf{1 5}]}\end{array}$ & No & No & Yes & No & Yes & generic \\
\hline $\begin{array}{l}\text { Bekhti } \\
{[\mathbf{1 6}]}\end{array}$ & Yes & Yes & Yes & No & Yes & generic \\
\hline $\begin{array}{l}\text { Harrani } \\
{[\mathbf{1 7}]}\end{array}$ & No & No & Yes & No & Yes & generic \\
\hline Sta [9] & No & Yes & Yes & No & Yes & generic \\
\hline
\end{tabular}


The set of models presented above could help to capitalize knowledge. This study allows us to note that:

- All the models are well-versed in the notion of reusing; they are generic models that could be profitable for all types of projects.

- The design logic is the most important component in the model. Effectively during the project leading, project team affronts many problems according to the design phase. So, all the models favor the capitalization of the design logic.

- No models allow the capitalization of project characteristics and subsequently they do not favor the documentation.

- Despite its importance in conducting projects, decision making process seems to be neglected by these models.

- Finally, we observe the absence of a model which guarantees the capitalization of all these elements at the same time: project context, project characteristics and design logic.

In the way to characterize correctly a computer research project and to organize and to structure the concept of computer project in general, it is very important at this stage to elaborate domain ontology of computer research project. Thus, we need first to have an idea about methodologies used to elaborate a useful ontology.

\section{B. Ontology Construction Methodologies (State-of-the-Art)}

In ontology engineering, the choice of methods, techniques and tools for the ontology construction process is an important step. Indeed, several methodological approaches have been proposed [18] to guide this process. We can distinguish four main categories of ontology development approaches:

- Ontology construction approaches from zero: For these methodologies, the sources of knowledge used for ontology construction are given by the domain experts [18]. Knowledge engineers are based on specific knowledge acquisition techniques such as brainstorming meetings, interview of experts, discussion, and knowledge extraction techniques, etc.

- Text-based construction approaches: This kind of methodology consists essentially of exploiting the textual resources [19] such as the projects documents and the lessons learned reports. They are generally applied for the construction of domain ontology.

- Approaches based on the reuse of already existing ontology: These approaches consist in exploiting the entire or a part of the knowledge contained in already developed ontology [20].

- Crowd sourcing based approaches: These approaches provide the outsourcing and the exploiting of tasks that are already performed by employees [18]. Knowledge engineers based their knowledge extraction on the direct observation of the tasks execution done effectively by employees. The essential goal is to formalize employees' experiences.
In our research work, we will be interested in the approach of building ontology from zero. Indeed, the construction of the proposed ontology follows an autonomous approach which is not based on any existing ontology or the updating of any other already constructed ontology.

Moreover, the knowledge and skills defining the essential components of the proposed ontology did not come from textual resources but from the deeper analysis of the domain of computer research projects.

For all the reasons mentioned above, we found ourselves obliged to adapt the construction approaches from zero to develop our domain ontology. In the following, we introduce the major works in the literature associated with this kind of approach.

1) Description of the main approaches from zero: Several works in the literature are oriented towards this type of approach in what follows we have discussed some proposals.

a) Two-steps Methodology: As its name indicates, this methodology is composed of two steps: 1) The knowledge organization and 2) the knowledge acquisition and reuse that allow the users collaboratively exploiting the knowledge [16]. In the beginning, a Core Reference Ontology (CRO) describing the generic concepts and relations according to the formalized requirements is identified. After, a Domain Specific Ontology (DSO) is specialized. Only two steps are not enough to describe a complete construction processes. In fact, this methodology is neither documented nor evaluated.

b) On-To-Knowledge Methodology (OTKM)[16]: It is a methodology based on acquired experiences of business activities. It is composed of four stages from identification, to documentation [21]. The stages are given implicitly and not explicitly [18]. The activities are few detailed (just a general description of the steps is given and no precision in the choice of components).

c) The Methodology Proposed by Fox and al [16]: This methodology is used in the context of the TOVE project (Toronto Virtual Enterprise). The application of this methodology is motivated by problems which are formulated under form of informal questions that ontology should answer. This methodology has made it possible to develop complex projects in the field of business but remains limited because neither the different stages nor the techniques used are precisely described [22]. This methodology is adapted only to informal knowledge description.

d) The Method Proposed by Noy [16]: This methodology is an iterative construction method that includes seven stages. Although this methodology is precise and well detailed, it is still incomplete. Indeed, no formalization and evaluation step is given in the process of construction. In addition, the description of the stages and the activities seems complicated and requires being a domain expert to achieve the ontology elaborating processes.

e) The Meth-Ontology: It is the most widely used methodology in literature [16]. It is the adopted construction approach for many anthologies in different fields. In fact, this method is highly-precise [27]. Meth-ontology can be applied 
in all areas, thanks to its flexibility. In fact, it can be applied in scratch or text approach.

In order to adopt an approach to construct our ontology, we will propose a comparative study between the methods already mentioned in the previous sub-section.

2) Comparative study of ontology construction methodologies: This comparative study is based on four criteria: these four criteria are selected in accordance with domain experts:

- Process step: this criterion informs on the way in which the construction process is defined: detailed, little detailed, or very detailed.

- Level of precision: the precision in the choice of the terms, relations and classes during the construction stages. This criterion differs from one method to another.

- Application domain: It serves to know in which domain this method has been applied.

- Type of activity: each process of construction is composed of a set of tasks or activities. Here, we have tried to determine the type of activity. Indeed, we can have a support activities, documentation, evaluation activities, etc.

This comparative study results in the choice of the "Methontology" as a methodology for ontology elaboration. Indeed, "Meth-ontology" is the most precise of all the previous methodologies. In addition, this methodology offers several types of activities and among these activities we mention project management.

The main orientation of this research study is to propose ontology in the field of research computer projects and particularly in project management domain. Since "Methontology" has a project management activity as an essential activity [16], and it permits to develop the ontology progressively by iterations, we have decided to use this methodology to build the proposed ontology.

It is in this context that we have proposed ontology for the domain of research computer projects. This methodology is incrementally elaborated:

- First we propose a modeling phase in which we elaborate a project model and a class project model. The model of a project defines the basic components of a project. The class model tries to target on the essential pillars of a class of projects. Our goal is to synthesize the characteristics and specific knowledge of a set of projects belonging to the same class: the same thematic of research unifying many different projects of research.

- Secondly, based on the previous models, we try to elaborate progressively the ontology of the domain of research computer projects. In this way, we elaborate first a kernel-ontology which represents the basic concepts known as essential to define a research project and we finalize our ontology step by step by adding branches and more details to well describe the domain of computer projects involved in research areas. So, our approach is called incremental approach which is mainly characterized by multi-intervention, documentation and iteration. In the next section, we will describe both the process of modeling of knowledge involved in Research computer projects and building ontology.

\section{KNOWledge Modeling Phase}

We will describe both the process of modeling Project and class of projects.

\section{A. Model of a Research Project}

A research project model 'Fig. 1' underlines three main components of the research project in the computer sphere:

- The project description is a textual description (Abstract / Keywords of the research project/ Title of the project).

- The project Characteristics enumerate all the items which characterize the conduction and the management of this research project such as (Time allowed for the project/ Cost estimated for the project/ Project steps / Project size/ Stakeholders involved/ Deliverables/ Constraints/Human resources/ Scope of project/...etc.).

- The project Rationale Design or Logic Design specifies all the problems and sub-problems encountered in the process of analysis, design, implementation and test involved in the project. This component is essential for the project because it focuses on logic problems, suggestions and solutions proposed by different actors implicated in the project phases and thus must be memorized for further reusing in the context of REX (Return of Experience). These main research problems are attached to specific research problems within a class of research theme. It is this component which could be exploited in knowledge capitalization. Effectively, all the knowledge involved in problem specification, suggestions proposed during problem solving process, and retained solutions are part of this component.

\section{B. Model of a Class of Projects}

A research class project model underlines three main components of the class of projects (Fig. 2) in the computer research sphere:

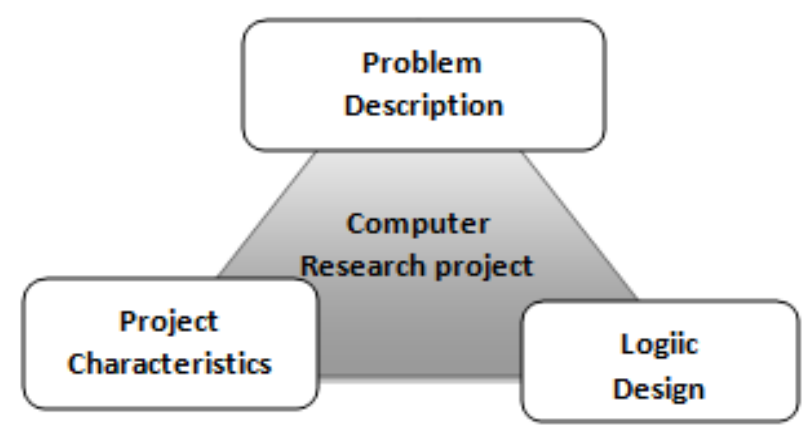

Fig. 1. Research Project Model. 


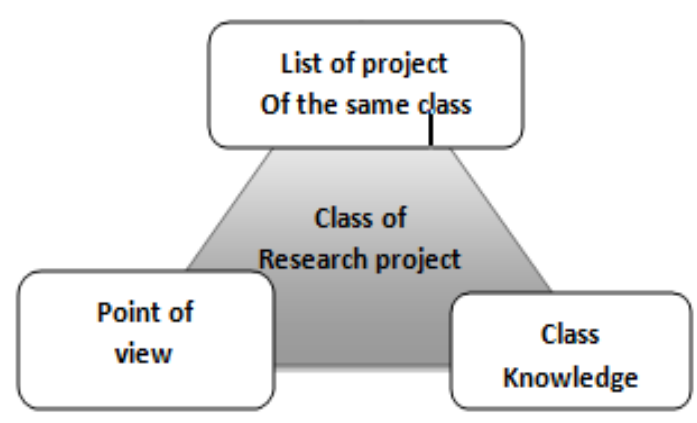

Fig. 2. Class Project Model.

- The List of projects is an extensive description of all the projects belonging to the same class and preclassified by domain experts (experts in research computer projects area);

- The Class project Knowledge stores all the forms of knowledge which characterize the conduction and the management of this research project class such as (research thematic/ Scope of this class project/ Methodologies / Kinds of design architecture/ Kinds of research problematic/ Systems/ support documentation/Rex reports/ main solutions approaches/ Appropriate tools, etc.)

- The Point of view for class project specifies different viewpoints and different strategies to manipulate knowledge involved in a class of projects. This component gives different manners for exploiting the same knowledge in the class. The point of view is attached to one particular actor and differs from one actor to another according to the aimed goals.

\section{Model of Rationale Design}

A rationale or logic design model underlines three main components of the project (Fig. 3) in the computer research sphere:

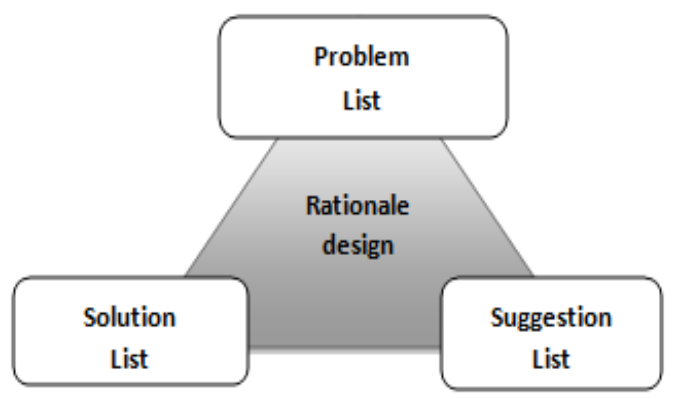

Fig. 3. Rationale Design Model.

- The List of problems is an extensive description of all the project research problems;

- The List of suggestions stores all the forms of suggestions introduced by researchers within the project area to solve the research questions or problems. The suggestion is a proposal to solve some research questions (research technique/ method of problem solving/ document/ tool/ algorithm/ strategy of solution/ issue of research/ etc.).
- The List of solutions specifies different solutions which could be adopted to solve a particular research problem.

\section{PROPOSED DOMAIN ONTOLOGY: ONTO-RESEARCH COMPUTER-PROJECT}

The proposal of a knowledge capitalization approach is the main goal of our current research study. This approach consists essentially of two processes:

- A knowledge formalization \& acquisition process.

- A support decision for project management process.

The present paper is only concerned by the first process. It is composed of two phases: The phase of formalization and the phase of knowledge acquisition.

This process is relayed by the proposal of domain ontology which structures and organizes the great mass of the concepts and knowledge encapsulated in the proposed models.

\section{A. Formalization Phase: Stages of Ontology Elaborating}

In this paper, we proposed an ontological construction approach based on the methodolgy "Meth-ontolgy" which leads to a final version of our domain ontology. We will now describe in detail this approach, by applying carefuly the methodology "Meth-ontolgy" wich has been selected in the basis of a comparative study (i.e. Section II-B.2). Finaly, we present a final version of the ontology (Fig. 10) with our proposed ontology validation approach.

The particularity of "Meth-ontology" is the possibility of the return on the steps preceding [25]. In what follows, inspired from "Meth-ontology", we will present the stages of the construction of our domain ontology:

- Step1: This step consists in building a glossary of terms containing all the domain knowledge that is useful and potentially usable for the construction of computer research domain ontology. This glossary includes concepts, instances, verbs and attributes. To do this step, we have met with domain specialists and experts to talk about computer projects. Fig. 4 gives a general idea on the knowledge areas recognized in PMBOK [26] reference as the essential rubrics to be considered in project management.

- Step2: In this step, we have built the first version of the ontology which presents the "classes' hierarchy": the hierarchy of concepts and terms obtained via the grouping, the categorization and the generalization of the different concepts studied (Fig. 5). This stage of modeling identifies three general Classes which are: the project description; the project characteristics; and the project logic design.

- Step 3: During this stage, we have created "relations between classes" by determining for each relation the type of relation and the classes to be connected (Fig. 6).

- Step 4: This step "instantiation of the ontology" consists in creating (individuals, instances) of the 
classes of general concepts. Each complete instance is a new case: a project. To achieve this stage of instantiation (Fig. 7) we used the database "Archive Hal" of computer research projects named "HALOuvertes".

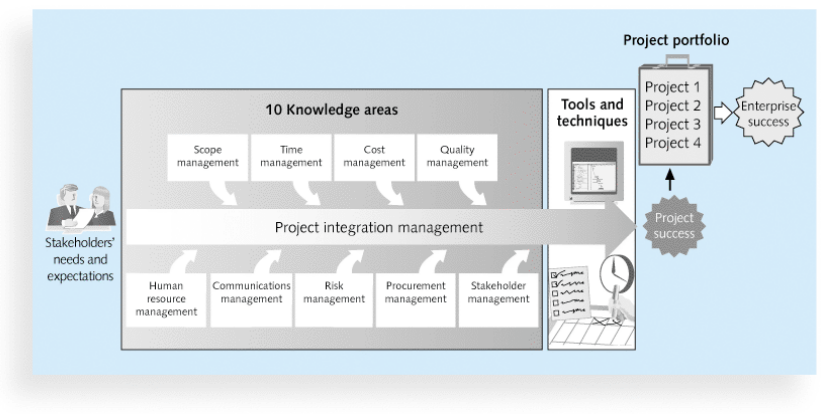

Fig. 4. Knowledge Areas of Project Management [26].

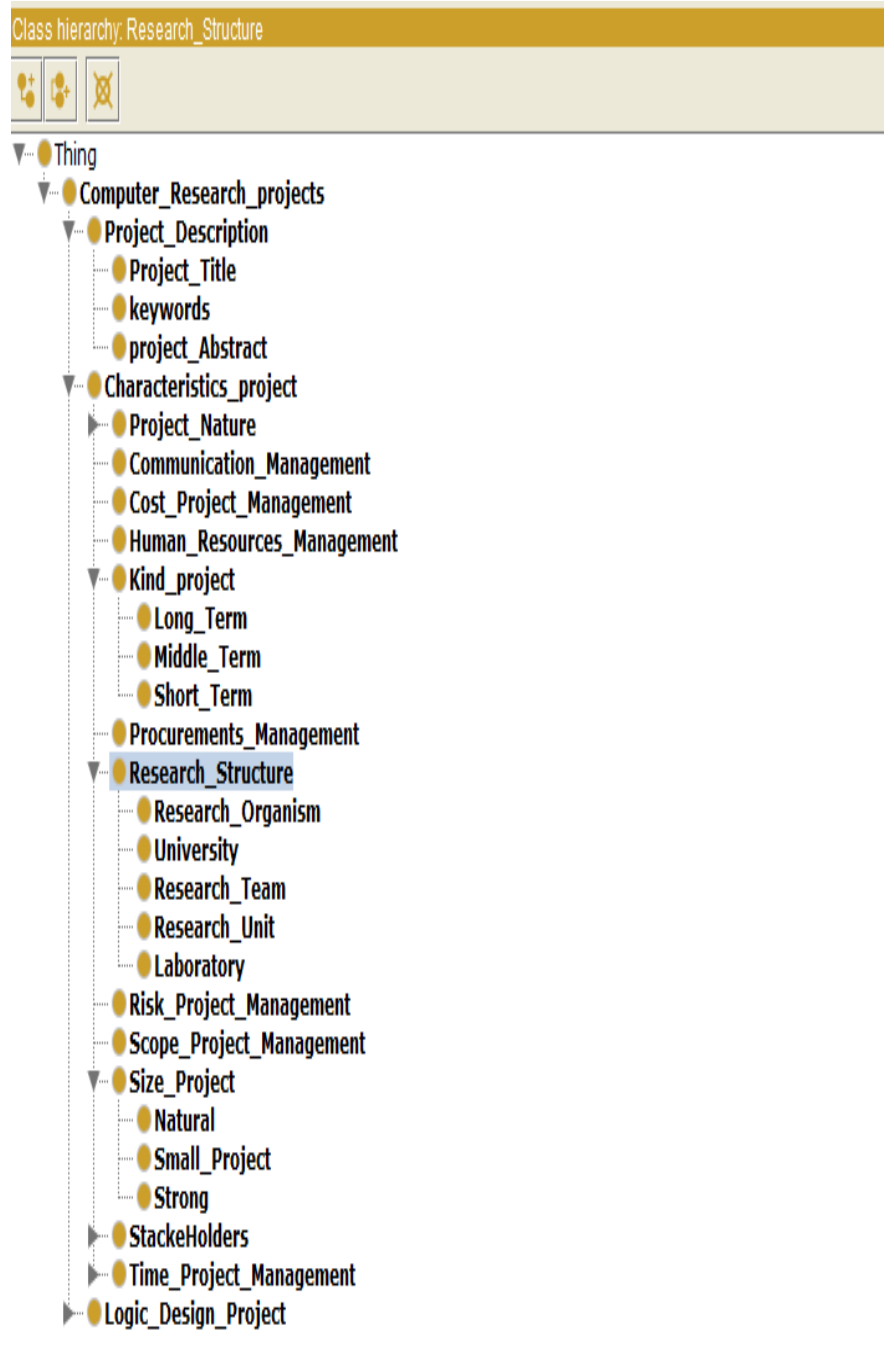

Fig. 5. Kernel Ontology: Class Hierarchy.

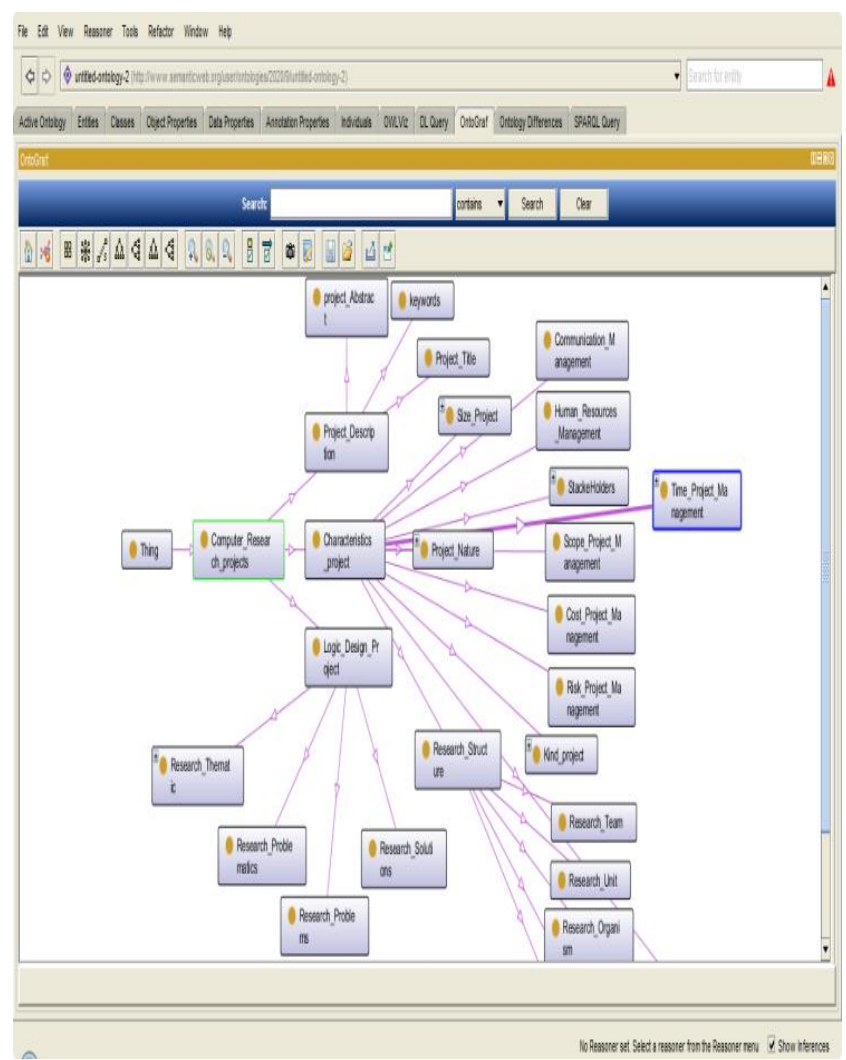

Fig. 6. Extract of Classes relations.

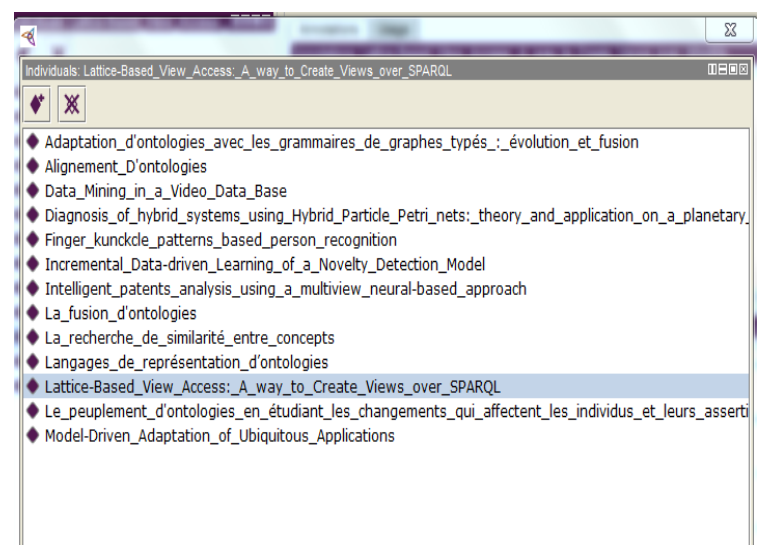

Fig. 7. Example of Individuals of Research Projects.

- Step 5: This step provides a detailed description of previously identified relationships, attribute concepts, and constants. We have used the research projects of the "Archive HAL" and the structure of documents to define some classes and some attributes (Fig. 8).

- Step 6: "Object properties". It concerns the description of formal properties, rules and axioms relating to the various elements of ontology. During this stage we will describe the set of properties and relations between the created individuals (Fig. 9). 


\begin{tabular}{|c|c|c|}
\hline Concepts & \begin{tabular}{|l|} 
Detailed \\
Description
\end{tabular} & Format of Concept \\
\hline \begin{tabular}{|l|} 
Project \\
Description
\end{tabular} & $\begin{array}{l}\text { An abstract of } \\
\text { project which } \\
\text { describes textually } \\
\text { a project }\end{array}$ & String of characters \\
\hline Project Title & $\begin{array}{|lr|}\text { A brief } & \text { title } \\
\text { identifying } & \text { the } \\
\text { project } & \\
\end{array}$ & String of characters \\
\hline Keywords & \begin{tabular}{|l|} 
The main \\
keywords max of \\
seven items
\end{tabular} & A list of 7 strings \\
\hline \begin{tabular}{|l|} 
Project \\
Characteristics
\end{tabular} & $\begin{array}{l}\text { A set of project } \\
\text { main attributes } \\
\text { lied to PM } \\
\text { knowledge areas } \\
\end{array}$ & A List of Characteristics \\
\hline Project Nature & Class of a project & \begin{tabular}{|lll} 
Item & belonging & to \\
["professiona/UnderGraduate/PostGraduate/Industria/Research
\end{tabular} \\
\hline $\begin{array}{l}\text { Communication } \\
\text { Management }\end{array}$ & \begin{tabular}{|l|} 
Aspects related to \\
Communication \\
Area of PM \\
\end{tabular} & 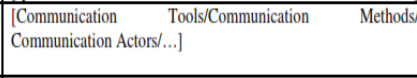 \\
\hline Cost Management & \begin{tabular}{|l|} 
Aspects related to \\
Communication \\
Area of PM \\
\end{tabular} & $\begin{array}{l}\text { [Earned Value/ Actual Cost/Planned Value/Cost Variance/Cos } \\
\text { Performance Index/Schedule Variance/Budget } \\
\text { completion/Estimate To Complete/Revised Budget/...] }\end{array}$ \\
\hline Time Management & $\begin{array}{l}\text { Aspects related to } \\
\text { Time Area of PM }\end{array}$ & $\begin{array}{l}\text { [First Start/ First Finish/ Late Start/ Latest Finish/Critical Path } \\
\text { Task Durations/ Float Activity/ Activity definition/ Activity } \\
\text { resources Estimation/Activities Scheduling/...] }\end{array}$ \\
\hline \begin{tabular}{|l|} 
Human Resources \\
Management \\
\end{tabular} & $\begin{array}{l}\text { Aspects related to } \\
\text { HR Area of PM }\end{array}$ & Details and processes of Human Resources PM \\
\hline Risk Management & $\begin{array}{l}\text { Aspects related to } \\
\text { Risk Area of PM }\end{array}$ & Details and processes of Risk PM \\
\hline & ..etc. & ..etc. \\
\hline \begin{tabular}{|l|} 
Kind Project \\
\end{tabular} & Type of project & Item belonging to [Short term/Long Term/Medium Term] \\
\hline Research Structure & \begin{tabular}{|l|}
$\begin{array}{l}\text { Organization } \\
\text { tutoring the project }\end{array}$ \\
\end{tabular} & $\begin{array}{l}\text { [ Laboratory / University / Team Project/ Industrial Office } \\
\text { Research Organism / Research Unit/ Association...] }\end{array}$ \\
\hline Scope PM & $\begin{array}{l}\text { The domain of } \\
\text { Research }\end{array}$ & $\begin{array}{l}\text { [Artificial Intelligence/ Data Science/ Data Mining/ Software } \\
\text { Eng / Networks / Operating Systems / Design Methodologies } \\
\text { Knowledge Eng./ Knowledge Management/Neural Networks.] } \\
\end{array}$ \\
\hline Size Project & \begin{tabular}{|l|}
$\begin{array}{l}\text { The Width of } \\
\text { project }\end{array}$ \\
\end{tabular} & [Small / Strong / Medium] \\
\hline $\begin{array}{l}\text { Deliverables } \\
\text { Project }\end{array}$ & $\begin{array}{|lr|}\begin{array}{l}\text { The } \\
\text { attended }\end{array} & \text { Outputs } \\
\text { project } & \text { for } \\
\end{array}$ & $\begin{array}{l}\text { [Report / Folders / Product / service / Results/ Lessons learned } \\
\text { Reports/ Recommendations/ Analyses] }\end{array}$ \\
\hline Stakeholders & $\begin{array}{l}\text { The actors of the } \\
\text { project }\end{array}$ & $\begin{array}{l}\text { [Sponsors/Customers/Users/Project Manager/ Project Team } \\
\text { Providers/Coaches..] }\end{array}$ \\
\hline Project Manager & $\begin{array}{l}\text { The chief of the } \\
\text { project }\end{array}$ & String specifying the position/ responsibilities/role \\
\hline Project Team & $\begin{array}{|lr|}\text { The ream } \\
\text { responsible of } \\
\text { achieving project }\end{array}$ & List of members and assigned roles \\
\hline ...etc. & ...etc. & \\
\hline
\end{tabular}

Fig. 8. Glossary of Concepts.

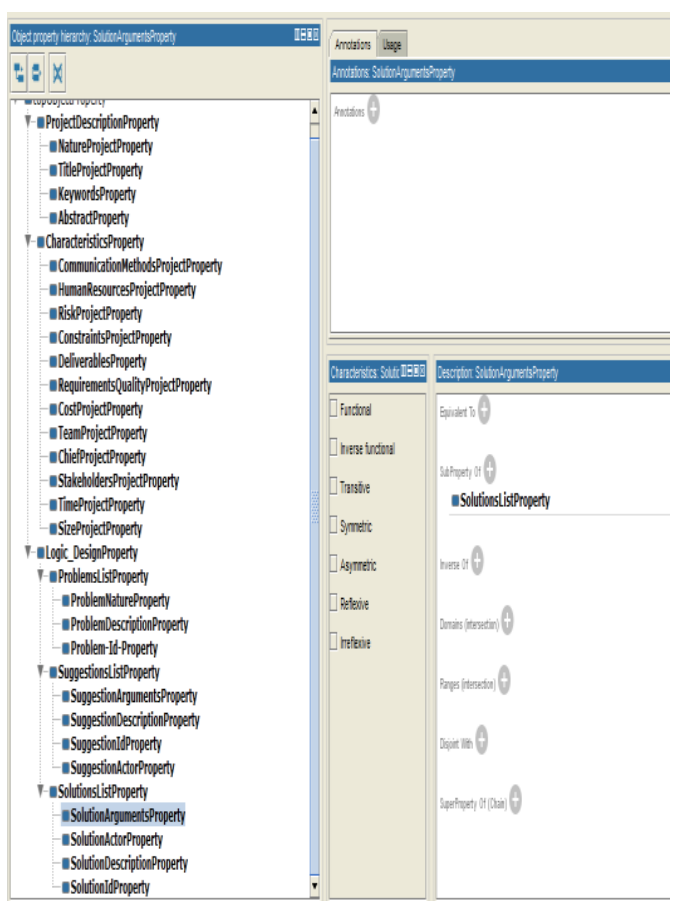

Fig. 9. Objects Properties.
- Step 7: This step concerns the detailed description of instances and relations between instances, classes and properties (Fig. 10).

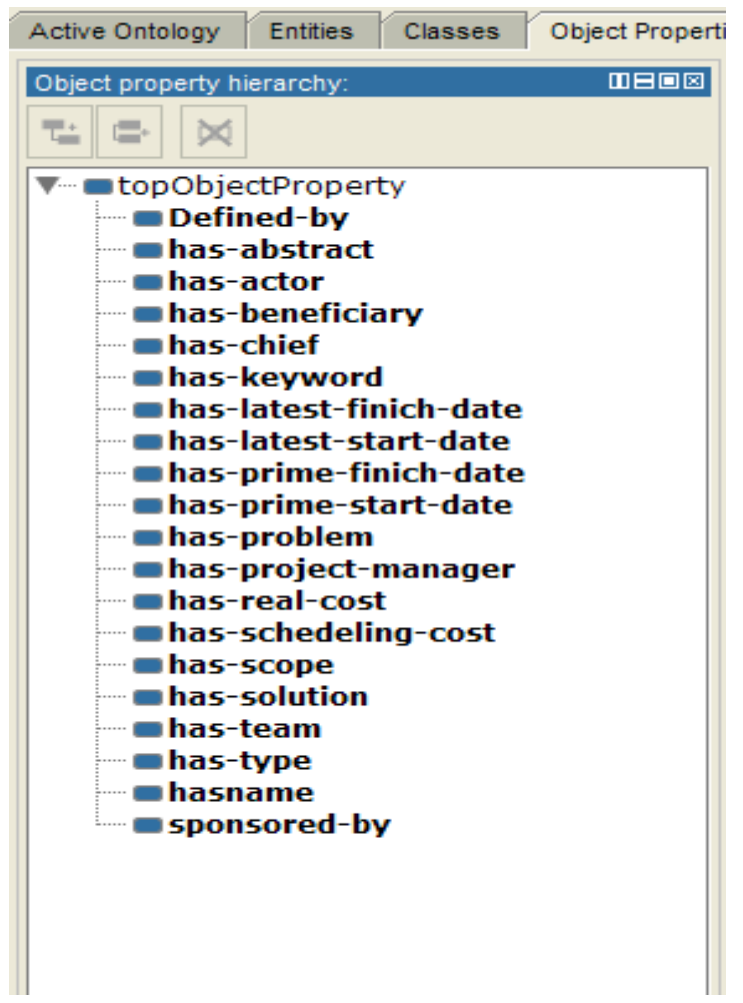

Fig. 10. Data Properties.

Validation ontology plays an important role during the creation and updating of ontology [27] to obtain a final and suitable ontology version (Fig. 11). This phase is done according two validation techniques: a structural and semantic validation [23], [28], [29], [30], [31], [32].

\section{B. Acquisition Phase}

The phase of project knowledge acquisition is essentially the acquisition of knowledge related to projects already achieved and completed. The project manager or one of the members of the project team will instantiate the set of concepts already introduced in the proposed ontology. The knowledge management is a complex process which requires many strategies [24].

Indeed, the scope, the characteristics and the rationale design describing each project will be stored. The list of collected projects play a main role in the decision support phase after, since they will be used for decision-making concerning the new projects in question.

In order to validate finally our approach and to test the functionalities offered by the aimed decision support system, we will choose to work on a specific type of computer project called "research projects". The choice of this type of projects is argued firstly by the fact that I' $\mathrm{m}$ actually a tutor of a young researcher and I'am aware of the problems and difficulties that any researcher can encounter when carrying out his project. Then, tests and applications on this type of project always still valid for the other projects type. 


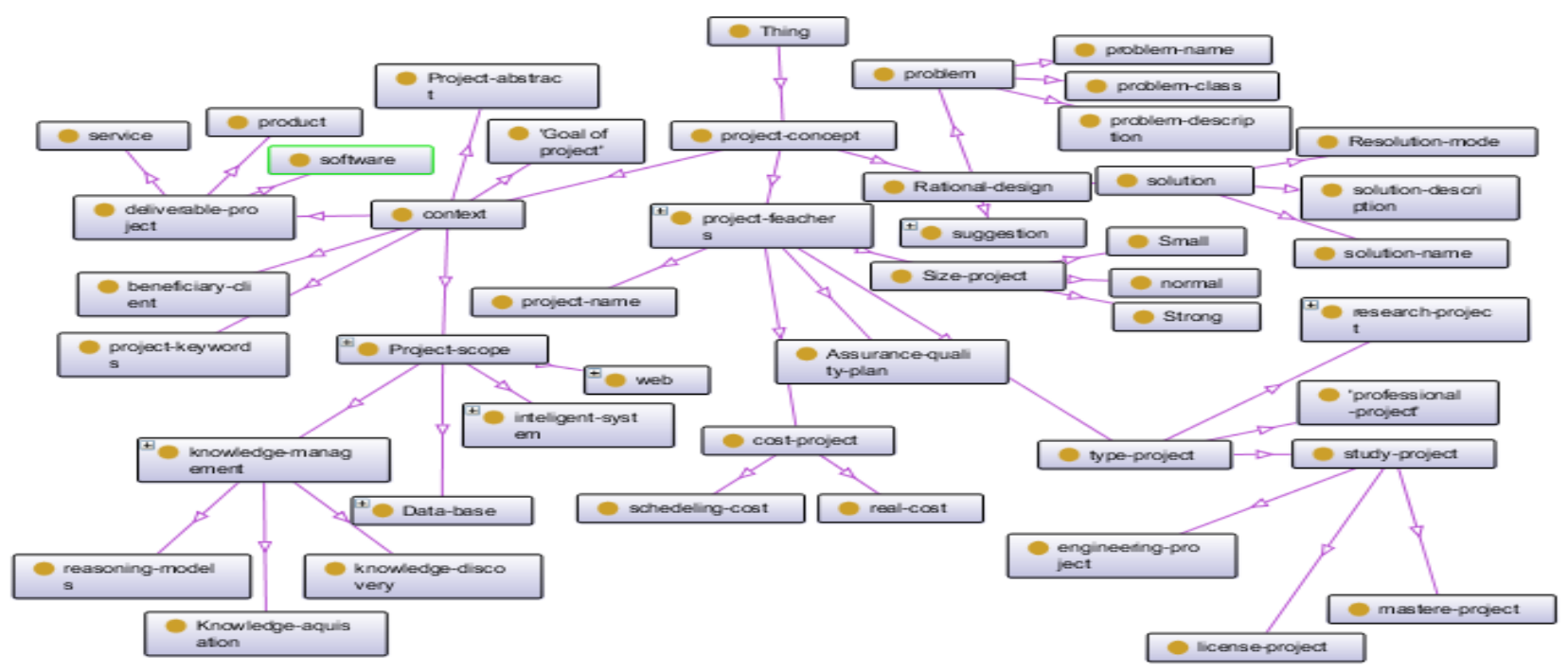

Fig. 11. Proposed Computer Domain Ontology Version.
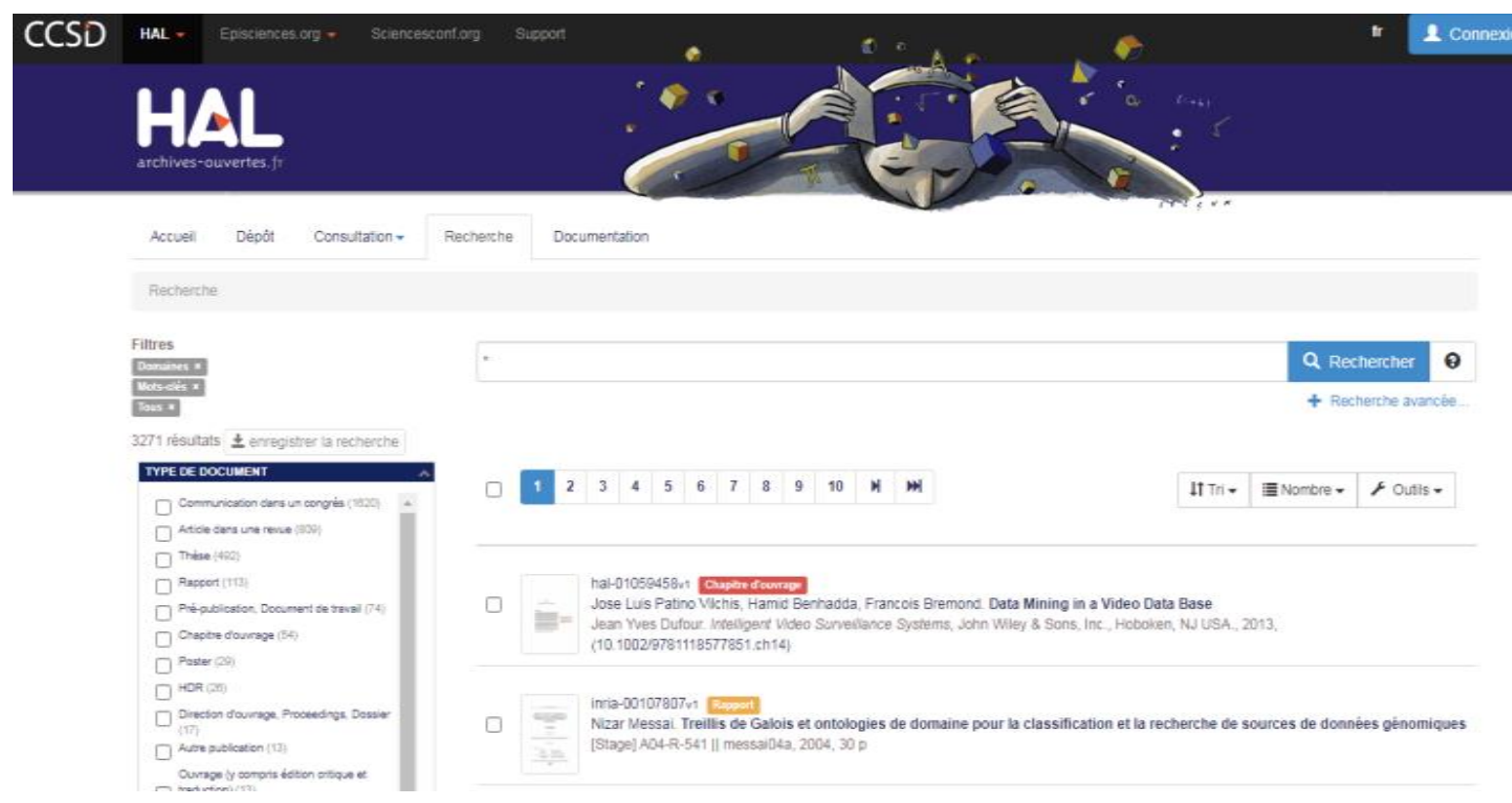

Fig. 12. Interface for Research Projects.

In this context we started with the construction of the knowledge base of the future system. This base is the results of an accumulation of projects published and validated in the Hal archive (almost 200 projects) structure (Fig. 12). We choose to work with 10 project scopes such as (ontology, database, big data, datamining, artificial intelligence, Networks, etc.).

\section{TOWARDS A FutURE SUPPORT DECISION APPROACH}

This approach is essentially composed of two processes:

- Formalization and acquisition of knowledge process.

- Project management assistance process.

The First process was described above in the precedent section and results in modeling of knowledge involved in research computer projects. This process is articulated essentially around the construction of the ontology of the domain of computer research projects concepts. The second process of assistance of project management is the object of this section and I will just introduce this process because it is yet in progress. We should give the general architecture of the target system (Fig. 13). This system aimed at supporting the decision making about research computer project. According to this goal, the project manager and the young researchers must be assisted by the system to make the convenient decision about their research topics. In the following, we will describe:

- The general description of the assistance process.

- The levels of help in decision making.

- The main modules of this system. 


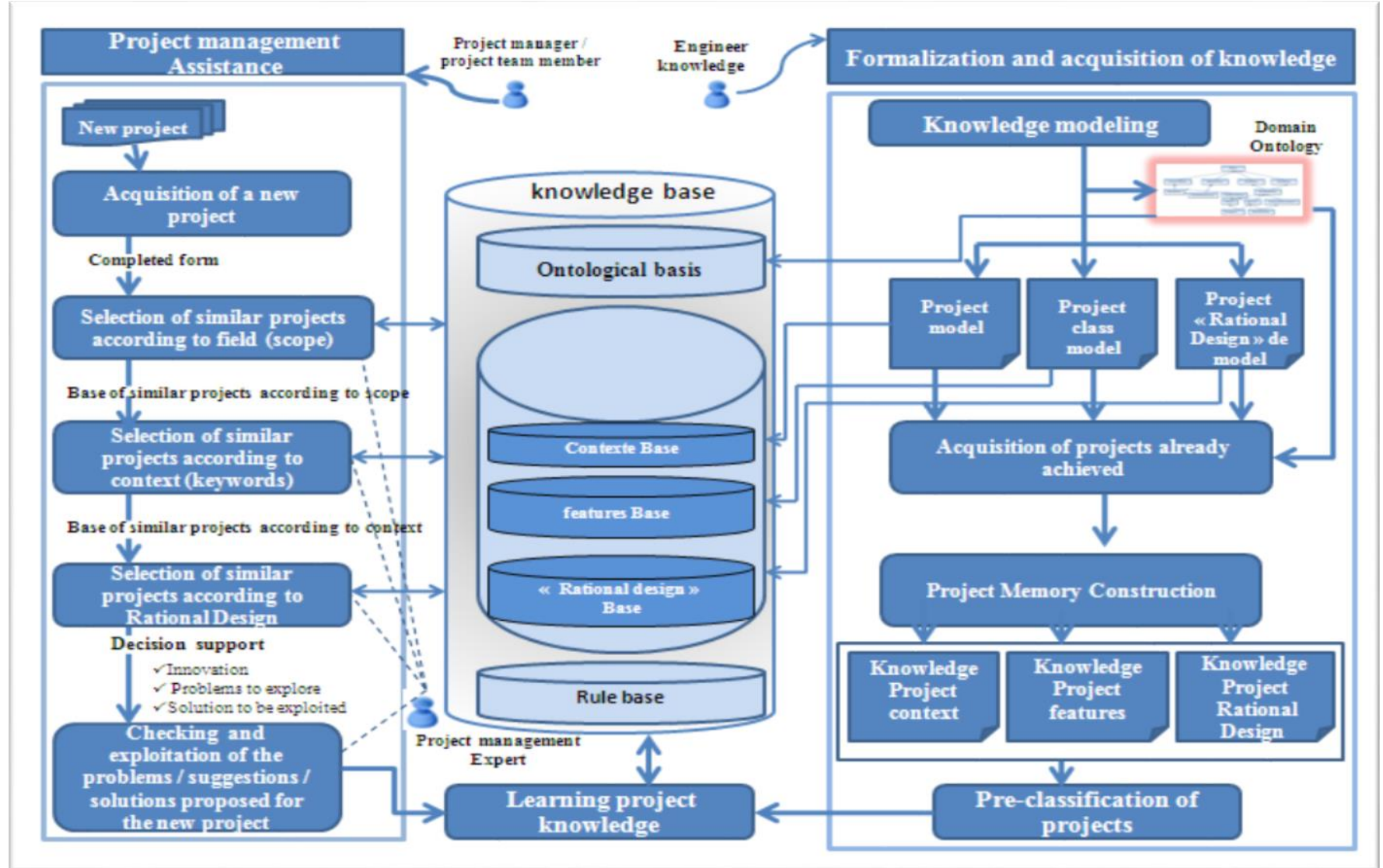

Fig. 13. Knowledge Capitalization Approach of Computer Research Project Memory.

\section{A. General Description of the Assistance Process}

This process begins with the acquisition of a new project and ends with the adding of this project, in the resolved form, to the project knowledge base. This process consists of four complementary sub-phases:

- Acquisition of a new project: The new project set by the project manager or the work team must be acquired as the first phase of the project management assistance process. In this situation, a form will be filled in containing all the characteristics defining this new project (context, characteristic, problems, Research theme, topics of research, actor ...).

- Selection of projects in the same scope: During this phase the list of projects belonging to the same project class will be displayed. The project manager (leader or member of the project team) must mention, from the beginning, the class (the scope) of the new project to be studied. Then, all the projects descriptions (characteristics, context and rationale design) of the class in question will be displayed. In this set of resulting projects, the rest of the manipulation and processing will be carried out. This phase of selection will reduce the workspace and search and will reduce the time of response.

- Selection of projects with the same context: this phase determine the set of projects that have the same working context (according to project keywords ...). During the acquisition of new project the keywords will be introduced and they will be used to calculate the similarity between the keywords of new project and the list of keywords of the old memorized projects. Here a new sub-base of projects which have the same class and the same context will be created.

- Selection of projects according to rationale design: This phase consists of filtering, in the sub-base created in the previous phase. It consists of checking and exploiting of problems/suggestions and solutions. This phase consists of verifying and validating the suggestions and the solutions proposed in historical projects and thus to reuse them for the resolution of new projects. This phase is carried out by the project manager.

- Learning of the new project: When the project is treated according to proposed solutions for all the research questions and problems inherent to this project, it must be considered as a new project achieved successfully and then could be archived in the project base. This phase operates as a learning phase which permits to restructure the knowledge base by adding this project. The project hence added is considered as a new case able to be reused for the resolution of other future new projects. 


\section{B. Levels of Help in Decision Making}

In the literature, there are several approaches, tools and decision support systems. Inspired by the approaches of what we have studied and others that are in the literature, we decided to offer a guide to project leaders. The main objective of this guide is to automate our proposed approach and to offer help on several levels. The specificity of our decision support system is that it will:

- Offer a guide or help to the project manager during the realization of the project and not at the end.

- Help the project manager with multiple levels of help, from acquiring the new project to solving and learning phases and lessons learned.

In order to properly describe the future decision support system, we give, here, an outline of three levels of assistance:

- The first level of help: it is a help oriented service. It allows the enrichment, consultation, statistics, framing and contextualization of new projects to be processed.

- The second level of help: it is a help oriented decision making. This level presents the main help offered by the system considering that it will favor project manager decision. Indeed a project can be launched in the case where it is innovative (never already treated). So it will start from zero and it will be considered as an innovative project.

- The third level of help: it is considered as a help oriented decision support. This level of help is achievable if the problems underlined in the new project have already been treated in historical projects. In fact, the user will benefit from these kinds of projects by making profit of the method used in problem solving, the techniques of development and the strategies already adopted to deal with the project conducting. The issues and the research steps already used in historical projects can be profitable for the new project as well as the problem solutions, suggestions and even the obtained results. It is also useful to exploit the failed projects and inspired from untreatable problems to invoke new trends and new research deals. Success as well as failure signaled in historical projects should be of great interest for new projects.

\section{The Main Modules of the Assistance System}

In this subsection, we will present the modules describing our proposed system and the application of involved levels of help in each module. Indeed, the system is defined by five modules: knowledge formalization module, acquisition module, project management assistance module, decision making module and learning module.

\section{- Acquisition \& formalisation modules}

These two modules can be applied to two types of projects (new and historical) we choose to proceed by three steps: context acquisition, features acquisition and finally Rationale Design acquisition. This choice shows the specificity of the decision support approach. Indeed, each part will be handled on a separate interface which facilitates access and management by different users.

The formalization of knowledge is done directly from the instantiation of the proposed domain ontology and the construction of a project memory.

- Project management assistance module

This module is the main module of the system. In this module, three levels of decision support are combined:

- The first level of decision support: selection of projects of the same class of the new project acquired. This selection is done thanks to a simple classification algorithm and requires that the achieved projects must be pre-classified (by project management expert).

- The second level of help is to determine the list of projects that have the same context. A similarity calculation algorithm will be applied to select projects that have a plausible similarity to the new project context. This level of help consists in selecting all the projects having similar keywords to the new project. The similarity rate adopted must greater than or equal to $75 \%$.

- The third level of help concerns the filtering of projects according to the proposed research problems contained in the new project.

\section{- Decision making module}

This module consists of making the final decision after the completion of the third level of filtering. Decision will be given automatically based on the result of the similarity calculation between the research problems of the new project and the set of research problems of the projects already selected from the knowledge base. In this situation, the user is concerned by one of three types of decision-making scenarios:

- First scenario of decision-making: in this situation, the similarity calculation rate is equal to zero. The user is informed that his project is an innovation and he must rely on his personal knowledge to solve his new project. In this situation the user can exploit the resulting information, knowledge and details in the first two levels of help. For example, he will see the list of problems encountered for projects in the same context. He can get an idea of the Rationale Design for this class of projects.

- Second scenario of decision-making: In this situation, projects that deal with the same type of problems are presented but they have not yet been solved (absence of the solution). The user can have an idea on the kinds of problems encountered for this type of research theme. In this case also the exploiting of the two other levels of help is possible.

- Third scenario of decision-making: In this case, the result of the similarity calculation shows that there are some projects that concern the same problems. In this situation, the user will solve the problems encountered 
in his project based on suggestions and solutions of similar selected projects.

- Learning module

For this learning module two learning functions are to realize:

- The first function concerns newly resolved projects. Projects with their problems, their suggestions and their solutions will be added in the project knowledge base using a learning algorithm.

- The second function concerns the acquisition of rules to elaborate a classification rule base.

\section{CONCLUSION AND FUTURE WORKS}

Our paper has an essential objective which is to support young researchers and teams in the selection of their research project in the way to avoid ambiguity and redundancy in research projects. This support cannot be done only by selecting the convenient project but also by supporting the conducting of the selected project during its execution essentially in phases of literature and in important phases of analysis and conception. That is in this perspective, why our word aimed to develop a support system organized by many levels of help.

Naturally, our work necessitates to structure and to organize all the heterogeneous knowledge involved in computer projects in research fields. Thus, this important phase of knowledge modeling require to be well managed and processed. Then, when knowledge manipulated in the context of research computer project is collected, structured and well organized, an acquisition of a base of computer research projects is processed in the way to construct a project memory.

This paper is reserved to present the first process of knowledge modeling and acquisition. The models presented in this paper concern a model of computer research project, a model of projects' class and a model of project rationale design. All these models are of great benefits for knowledge structuring and organizing. After the modeling and the formalizing knowledge involved in the domain of computer research projects, the knowledge representation is a crucial mission. Thus, the ontology of the computer research projects domain was designed.

Validation ontology plays an important role during the creation and updating of ontology to obtain a final and suitable ontology version. This phase is done according two validation techniques: a structural and semantic validation. These two validation techniques are complementary to deal with an acceptable ontology. Evaluating ontology means checking and validating two aspects: structural aspect and semantic aspects. The validation of the structural aspect of ontology allows verifying the consistency and the coherence of a model to check. In this way, classes and sub-classes are verified according to criteria of consistency and coherence between them and to avoid redundancy.

The validation of the semantic aspects involves communication aspects between actors of different domains of expertise. In this way, we proposed a validation approach based on two criteria:

- The first criterion: the Incremental validation of the ontology: the passage from one validation step to another results in an update [modification, deletion or addition] of the initial ontology.

- The second criterion: the Multi-intervention criteria: This approach is characterized by the intervention of several and different experts. Three experts are involved in the validation process:

- The project management expert: He is an expert in the field of project management.

- The project computer expert: He is an expert who masters all the concepts of computer projects.

- The specialist in ontology engineering: this actor has a good command of all the tools and editors of the ontology.

Because the present paper was reserved to present the process of knowledge modeling, formalization and acquisition, different stages of ontology construction were given. We have also introduced here the general approach for exploiting ontology to construct a computer research project memory which could be after used by young researchers in computer science and computer engineering domains to help them to evaluate if their research themes and/or research problems proposed in their research projects are already treated by others before them or if they innovative.

Even, if their research projects are already treated, the approach introduced in this paper seems to help them to exploit the solutions and/or suggestions and issues and techniques proposed within the rationale design of historical projects archived to launch new issues or new approaches for solving the same problems or to process new problems. Although the approach seems interesting in the articulation of stages and main ideas and concepts involved, it still needs to be validated experimentally by its application on ontology of domain and on real research projects such the examples of HAL archives.

Then we have to implement in the future the modules proposed in our approach to validate the proposal and by the means of machine learning techniques we have to construct a knowledge base able to be exploited in helping young researchers in decision process. We have to validate and test the base knowledge. However, this part of work still insufficient it's always necessary to design approaches and to organize knowledge before implementation and tests.

For future work, we will focus on developing a prototype system to evaluate the feasibility of the whole approach.

\section{REFERENCES}

[1] J.Gherasim, M.Harzallah , G. Berio and P. Kuntz , "Comparative analysis of methodologies and tools automatic ontology construction from textual resources", LABSTICC, UMR 3192 CNRS, January, (2014).

[2] N.Matta, G.Ducellieret and H. Atifi, "Learning from design projects: how to keep track and learn from knowledge produced in daily activity", ICD, University of Technology of troyes ,france (2016). 
[3] E. Lauraine, "IT project management", Digital business space, June (2017).

[4] P. Collet, "Computer Project", University of Nice, France (2014).

[5] Ch.Huang, W. liang, T.Tseng and R. Wong, "A rough setbased corporate memory for the case of ecotourism", Tourism Management Journal, Elsiever, Vol 47, pp. 22-33 April (2015).

[6] F.Rauscher, N.Matta and H.Atifi, Hybrid System for Collaborative Knowledge Traceability An Application to Business Emails, In Proceedings of the 7th International Joint Conference on Knowledge Discovery, Knowledge Engineering and Knowledge Management-Vol 3: KMIS, pp.260-267, Lisbon, Portugal,(2015).

[7] J. : J.A.Duarte, "An Analysis Of The Recommended Knowledge For The Software Project Management Discipline", Thesis presented as part of the project management master's program, Polytech University, Madrid, June (2014).

[8] L.Boubaker, L.Mellal, M.Djebabra, "Model DIK (Data - Information Knowledge) Support tool for the development of project briefs", The Journal of Management Sciences 2010/3 ( ${ }^{\circ}$ 243-244), pp. 153-159. DOI 10.3917 / rsg.243.0153, (2010).

[9] H.BenSta, "Contribution of the conceptual modeling to knowldge engineering management: application in the framework of the project memory", thesis Lille 1, (2006).

[10] V.Marinela, L.Anica, I.Anica, "Organizational Memory: an Approach from Knowledge Management and Quality Management of Organizational Learning Perspectives", Amfiteatru Economic 11(26):473-481, June (2009).

[11] A. André, "Organizational memory breaks with individual memory", Communication and organization [Online], 24 | 2004, posted online 19 December 2012, accessed on 01 October (2016).

[12] J.Pomian, "Corporate memory, techniques \& tools for knowledge management". Ed Sapienti, (1996).

[13] R.Dieng, O. Corby, A.Giboin and M.Ribiere, "Methods and Tools for Corporate Knowledge Management",RR-3485,INRIA.inria-00073203, (1998).

[14] J.Bascans, M.Chevalier, P.Gennero and Ch.Soul'e-Dupuy, "Adaptive organizational memory for automatic classification for information capitalization". 33rd Computer Congress of Organizations and Information and Decision Systems (INFORSID 2015), May (2015).

[15] M.Labrousse, "Proposing a Unified Conceptual Model for the dynamic management of Corporate Knowledge", thesis of the central school of nantes specialty mechanical engineering, 13 July (2004).

[16] S.Bekhti, "DYPKM: A Dynamic Process for Defining and Reusing Project Memory", Human Machine Interface [cs.HC], Troyes University of Technology, (2003).

[17] Y.Harani, "A Multi-model Approach for the Capitalization of Knowledge in the Field of Design", thesis of the INPG, specialty in Industrial Engineering, November (1997).
[18] F.Rauscher, N.Matta and H.Atifi, "Hybrid System for Collaborative Knowledge Traceability An Application to Business Emails", Second IFIP WG 12.6 International Workshop, AI4KM 2014, Warsaw, Poland, September 7-10, (2014).

[19] A.Amarir, El.Benlahmer and L.Elhoussine, "The Methods of Building ontology from text", Conference Paper, The second day on Information Technologies and Modeling TIM'14, May (2014).

[20] E.G.Caldorala, A.M.Rinaldi, "An Approach to Ontology Integration for Ontology Reuse" Conference Paper, IEEE 17th International Conference on Information Reuse and Integration, At Pittsburgh, Pennsylvania, USA, July (2016).

[21] K. Drame, "Contribution to Ontology Construction And Information Retrieval: Application To Tthe Medical Field," thesis, Bordeaux University, France. ffNNT : 2014BORD0444 (2014).

[22] J.Gherasim, M.Harzallah , G. Berio and P. Kuntz , "Comparative Analysis of Methodologies and Tools Automatic Ontology Construction From Textual Resources, LABSTICC, UMR 3192 CNRS, 8 Jan (2014).

[23] B.Menaouera, S.Khalissab , B.Abdelbakic , T.Abdelhamidd "Towards a new approach of support innovation guided by knowledge management: Application on FERTIA, 4th International Conference on Leadership, Technology, Innovation and Business Management, Procedia - Social and Behavioral Sciences 210, 260 - 269, (2015).

[24] A.Amarir, El.Benlahmer and L.el houssine, "The methods of building ontology from text", Conference Paper, The second day on Information Technologies and Modeling TIM'14, May (2014).

[25] M.Richard, X.Aimé, M.Krebs and J.Charlet, "LOVMI: Towards an Interactive Method For The Validation of Ontologies“, INSERM UMRS 1142, LIMICS, F-75006, Paris, France ,IC, (2015).

[26] https://www.pmi.org/pmbok-guide-standards, 2021 Project Management Institute, Inc.(2021).

[27] G.Michael "Ontology Validation as Dialogue", 4.0 International (CC BY 4.0), eur-ws.org/Vol-2518/paper-WINKS3.pdf, (2019).

[28] A.Yunianta et al, Methodology for Ontology Development on Data Integration (OntoDI), (IJACSA) International Journal of Advanced Computer Science and Applications, 2019.

[29] S.Tartir,S.Amit,I.Arpinar and Young, "Ontological Evaluation and Validation, From Book Theory and Applications of Ontology" Computer Applications (pp.115-130), (2010).

[30] B.A.Asma, M.Silveira, C.Pruski, "An approach for content validation of an ontology by a system based on questions answers", CR SANTEC Centre de Recherche Public Henri Tudor ,July (2013).

[31] G.Leila,M.aya and D.faiza,“ Generation of A Questionnaire From A Domain Ontology,Conference paper, (2017).

[32] G.Alex, B.P.Chavez and M.Davy,"Methodology to Design Ontologies from Organizational Models: Application to Creativity Workshops", 14 décembre 2020. 